http://jmscr.igmpublication.org/home/ ISSN (e)-2347-176x ISSN (p) 2455-0450

crossref DOI: https://dx.doi.org/10.18535/jmscr/v7i10.19

Journal Of Medical Science And Clinical Research

\title{
A prospective Comparative Study of Acceptability, Efficacy and Safety of Medical Method of Abortion versus Manual Vacuum Aspiration in Termination of Pregnancy up to 7 weeks gestation
}

\author{
Authors \\ Dr Nalneesh Sharma ${ }^{1 *}$, Dr B.R.Sharma ${ }^{2}$, Dr Hamender Mahajan ${ }^{3}$, Dr Reena Sharma \\ ${ }^{1}$ Assistant professor OBG, SLBSGMCH Mandi, ${ }^{2}$ Professor OBG, GMCGMCH Mandi \\ ${ }^{3}$ Assistant Professor, SLBSGMCH Mandi, ${ }^{4}$ Assistant Professor, SLBSGMCH Mandi \\ *Corresponding Author \\ Dr Nalneesh Sharma
}

\begin{abstract}
Background: The objective of present study was to compare the safety, efficacy and acceptability of medical method of abortion versus manual vacuum aspiration in early pregnancy termination upto 7 weeks of gestation.

Methods: A prospective comparative study was conducted at KNH-IGMC Shimla from $1^{\text {st }}$ August, 2015 to $31^{\text {st }}$ July2016 on 100 pregnant women who were willing for termination of pregnancy up to 7 weeks (49 days) of gestational age, in Group A: women who opted for medical method for termination, Group B: women who opted for manual vacuum aspiration for termination.

Results: Out of 100 women selected for termination of pregnancy after fulfilling the criteria 62 women had opted the medical method and 38 had opted for MVA. Majority of women residing in urban area preferred for medical method but women from rural area opted MVA to avoid repeated visits. Majority of women opted medical method as it was less painful and not traumatic. Minor side effects like nausea, vomiting and diarrhea were more common among women opted medical method. There were no major complications in any of group like cervical injury, uterine perforation and blood transfusion. Success rate was more with MVA than medical method (97.3\% vs 93.5\%). However satisfaction rate was more with medical method than MVA (91.9\% vs 89.5\%). Women of both the groups admitted that they would advise the same method to others if needed.

Conclusions: It is concluded from the present study that MVA and medical method both are simple, safe and easy procedures and does not require any special skill. We should allow women to choose the method of termination. This will increase their acceptability, particularly at $<7$ weeks gestation.
\end{abstract}

Keywords: Contraception, manual vacuum aspiration (MVA), medical abortion, Misoprostol, Mifepristone.

\section{Introduction}

Induced abortion is a controversial topic that invites emotional and controversial debate. Unwanted pregnancy is a problem that can never be resolved fully. A woman who does not wish to continue a pregnancy will seek any mean to terminate, regardless of safety ${ }^{1}$. Each year about 210 million women become pregnant and over 75 million pregnancies end in stillbirth or spontaneous or induced abortion. About 42 million pregnancies are terminated voluntarily, 22 milloin safely and 20 million usafely ${ }^{2} .98 \%$ of 
these unsafe abortions are done in developing countries $^{3}$. These unsafe abortions contribute to $10-15 \%$ of maternal deaths in these developing countries ${ }^{4}$. Although unsafe abortions are preventable, they continue to pose danger to women's life ${ }^{2}$. Thus a search for safe and cost effective method for termination of pregnancy continues.

To decrease the incidence of illegal abortions, Government of India has passed MTP Act, 1971 and has fixed certain norms for place, person doing MTP and indications for termination of pregnancy. Following are the indications for termination under MTP Act 1971:

1) To save the life of mother.

2) Social indications: To prevent the grave injury to the physical and mental health of pregnant women like when pregnancy is caused by rape.

3) Eugenic ground: When substantial risk of the child being born with serious physical and mental abnormalities not compatible with life.

4) Pregnancy that is because of contraceptive failure.

MTP by medical method has advantage of being inexpensive, non-invasive and it is an office procedure. Disadvantage is that it may cause GI upset and $8-10 \%$ may require an additional surgical procedure. Manual vacuum aspiration is another effective method which is safe and highly effective office procedure, only local anesthesia with less patient morbidity and quick recovery and resumption of normal activity ${ }^{1}$.

\section{Methodology}

A prospective comparative study was conducted at KNH-IGMC Shimla from $1^{\text {st }}$ August, 2015 to $31^{\text {st }}$ July 2016 on 100 pregnant women who were willing for termination of pregnancy up to 7 weeks (49 days) of gestational age. The aim of study was to compare acceptability, efficacy and safety of medical method, using mifepristone and misoprostol and manual vacuum aspiration (MVA) at less than or equal to 7 weeks of gestation. After taking informed and written consent Study population was divided into two groups according to women's desire. Allocation was done as per their choice of method for termination of pregnancy.

Group A- Women who has opted medical abortion with mifepristone and misoprostol.

Group B- Women who has opted surgical method using manual vacuum aspiration.

\section{Inclusion Criteria}

1. Age between 18 to 39 years.

2. Confirmed viable singleton intra-uterine pregnancy.

3. Less than or equal to 7 weeks gestation.

4. Requesting elective termination of pregnancy.

5. Willing to return for follow up visit.

\section{Exclusion Criteria}

1. Anemia haemoglobin $<8 \mathrm{gm} \%$.

2. Suspected or confirmed ectopic pregnancy.

3. Women with known hypersensitivity to mifepritone.

4. Women with hemorrhagic disorders or on anticoagulants.

Total 100 women desiring termination of pregnancy of 7 weeks or less, fulfilling criteria were recruited in the study. Written informed consent was taken from all the participants. Detailed clinical, menstrual, contraceptive and obstetrical history was taken. Clinical examination including general physical and systemic examination was done. Bimanual Pelvic examination was done to know the position, size and mobility of uterus the presence of infection. The hematological investigation included like $\mathrm{CBC}$, blood grouping and $\mathrm{Rh}$ typing, Blood sugar level and urine routine microscopy was done. Patients were verbally explained about the advantages and limitations of medical and MVA for termination of pregnancy. Then they were allowed to choose any one of the method. Women was asked the reason for choosing the particular method, whether advised by friend, relative or decided by self. All details were entered in the 
proforma. Written consent for MTP was taken. Data collected and analyzed statistically.

\section{Medical Method}

After confirming gestational age and written informed consent, following regimen was followed. All norms as per the MTP act by the government of India were followed. On first visit (Day 0) of medical abortion Mifepristone 200 mg was given orally. The patient was asked to keep tab. Misoprostol 400ug per vaginally on second visit (Day 2 i.e. after 48 hrs) in hospital. Kept and was observed for 4 hours in a day care. After 4 hours a vaginal examination was done to see the onset of abortion process. Patient was explained that bleeding could be prolonged up to 8-10 days. Women were called for third visit (follow-up on 14 day) and clinical evaluation was done to ensure that abortion is complete.

Women were asked to note onset of bleeding, timing of passage of product of conception, duration of bleeding and side effects. In case heavy bleeding/severe pain she should have reported to hospital immediately. Ultrasound was done if patient with excessive bleeding. Success was defined as complete expulsion of products of conception with no need for surgical intervention.

\section{Surgical Abortion (MVA)}

All women who had opted surgical abortion underwent operation following standard procedures under local anesthesia. Sterilized MVA syringe with appropriate size canula was taken. P/V examination was done. After inserting speculum in to vagina, the cervix and vagina was sterilized with povidine iodine. Appropriate size canula was inserted. Then MVA syringe was attached and contents were aspirated. Presence of villi on fresh tissue confirmed the success of procedure. Each woman was observed for at least for four hours after the procedure. Vitals were checked before discharge.

Prophylactic anti-D (300microgram) was given to all $\mathrm{Rh}$ negative women. Details of procedure and any per operative complications were recorded.
All patients were followed up after two weeks to look for any RPOC's and post operative hemoglobin. They were asked about any side effect of the procedure, procedure acceptability and whether they will recommend the same procedure to others.

\section{Results}

A prospective comparative study was conducted at KNH-IGMC Shimla from $1^{\text {st }}$ August, 2015 to $31^{\text {st }}$ July 2016 on 100 pregnant women who were willing for termination of pregnancy up to 7 weeks (49 days) of gestational age. In

Group A: women who opted for medical method for termination were 62 in number.

Group B: women who opted for manual vacuum aspiration for termination were 38 in number.

Table No. 1 Distribution of clients by type of method opted by them.

\begin{tabular}{|l|c|c|c|}
\hline Method & $\begin{array}{c}\text { No. of } \\
\text { women }\end{array}$ & percentage & P value \\
\hline $\begin{array}{l}\text { Medical } \\
\text { method }\end{array}$ & 62 & $62 \%$ & \\
\hline MVA & 38 & $38 \%$ & \\
\hline Total & 100 & $100 \%$ & $<0.05$ \\
\hline
\end{tabular}

Out of 100 women recruited in study, 62 had chosen medical method and 38 had vacuum aspiration which was significant statistically (p value < 0.05), which is comparable with the studies done by Malatu et al. So women had preferred non invasive medical methods over invasive surgical methods.

Table No. 2 Distribution \& comparison according to residence of client in both methods

\begin{tabular}{|l|c|c|c|c|}
\hline Residence & $\begin{array}{c}\text { Medical } \\
\text { method }\end{array}$ & MVA & P value & \\
\hline URBAN & $40(64.5 \%)$ & $\begin{array}{c}12 \\
(31.6 \%)\end{array}$ & $<0.01$ & \\
\hline RURAL & $22(35.5 \%)$ & $\begin{array}{c}26 \\
(68.4 \%)\end{array}$ & 0.1 & \\
\hline Total & $62(100 \%)$ & $38(100 \%)$ & & \\
\hline
\end{tabular}

More women from rural background have chosen the MVA, reason being to avoid the repeated visits to health institutions. Urban women had chosen medical method; this could be due more education and easy accessibility to health services. 
Results were statistically significant i.e. p-value $<0.01$.

Table No.3 Distribution \& comparisons on the basis of educational status of client in both methods.

\begin{tabular}{|l|c|c|c|c|}
\hline Education & Total & $\begin{array}{c}\text { Medical } \\
\text { method }\end{array}$ & MVA & $\begin{array}{c}\text { p- } \\
\text { value }\end{array}$ \\
\hline Illiterate & 5 & $2(40 \%)$ & $3(60 \%)$ & 1 \\
\hline Primary & 15 & $6(40 \%)$ & $9(60 \%)$ & 0.4 \\
\hline Secondary & 20 & $10(50 \%)$ & $10(50 \%)$ & 0 \\
\hline $\begin{array}{l}\text { Higher } \\
\text { education }\end{array}$ & 60 & $44(73.3 \%)$ & $16(26.7 \%)$ & $<0.01$ \\
\hline
\end{tabular}

It was observed that having higher education had more preference for medical method. The results are comparable with study done by Mulatu et al with significant $\mathrm{p}$ value.

Table No.4 Distribution \& comparison on the basis of socio-economic status of client in both methods.

\begin{tabular}{|l|c|c|c|c|}
\hline $\begin{array}{l}\text { Socioeconomic } \\
\text { status }\end{array}$ & Total & $\begin{array}{c}\text { Medical } \\
\text { method }\end{array}$ & MVA & $\begin{array}{c}\text { p- } \\
\text { value }\end{array}$ \\
\hline Upper class & 7 & $5(71.4 \%)$ & $2(28.6 \%)$ & 0.2 \\
\hline $\begin{array}{l}\text { Upper middle } \\
\text { class }\end{array}$ & 18 & $12(66.7 \%)$ & $6(33.3 \%)$ & 0.09 \\
\hline $\begin{array}{l}\text { Lowermiddle } \\
\text { class }\end{array}$ & 32 & $22(68.7)$ & $10(31.3 \%)$ & $<0.01$ \\
\hline Lower class & 43 & $23(53.4 \%)$ & $20(46.5 \%)$ & 0.6 \\
\hline
\end{tabular}

It was observed that no significant difference was detected in method choice in women of different socio-economic class except in lower middle class, showing preference for medical method.

Table No. 5: Comparison of side effects observed by client in both methods.

\begin{tabular}{|l|c|c|c|}
\hline Side effects & $\begin{array}{c}\text { Medical } \\
\text { method }\end{array}$ & MVA & p-value \\
\hline Nausea & $18(29 \%)$ & $8(21 \%)$ & 0.5 \\
\hline Vomiting & $4(6.4 \%)$ & $2(5.2 \%)$ & 1 \\
\hline Diarrhea & $4(6.4 \%)$ & $1(2.6 \%)$ & 0.7 \\
\hline $\begin{array}{l}\text { Duration of } \\
\text { bleeding }\end{array}$ & $6.7+\_5$ & $3.6=\_3$ & \\
\hline Pain & $10(16.1 \%)$ & $18(47.3 \%)$ & $<0.01$ \\
\hline
\end{tabular}

It was observed that medical method caused more G.I disturbance due to drug effect as compared to MVA. Bleeding time was also more in medical method. However the pain felt by the patient in
MVA was more than medical method (p-value $<0.01$ ). Results are comparable with study done by Nhu Ngoc et al.

Table No. 6: Comparison of outcome in both methods.

\begin{tabular}{|l|c|c|c|}
\hline $\begin{array}{l}\text { Method } \\
\text { Outcome }\end{array}$ & $\begin{array}{c}\text { Medical } \\
\text { method }\end{array}$ & MVA & p-value \\
\hline $\begin{array}{l}\text { Complete } \\
\text { abortion }\end{array}$ & $58(93.3 \%)$ & $37(97.3 \%)$ & 0.7 \\
\hline $\begin{array}{l}\text { Incomplete } \\
\text { abortion }\end{array}$ & $4(6.6 \%)$ & $1(2.7 \%)$ & 0.7 \\
\hline $\begin{array}{l}\text { Pregnancy } \\
\text { cont. }\end{array}$ & 0 & 0 & \\
\hline Sepsis & 0 & 0 & \\
\hline
\end{tabular}

Patient had complete abortion in $93.3 \%$ of cases after medical method and results are comparable with study done by Sreeja GR at $\mathrm{el}^{7}$. Patient had complete abortion in $97.3 \%$ after MVA and results are comparable with study done by Mohamed Abd Elzaher et $\mathrm{al}^{8}$.

Table No. 7: Comparison of acceptability of both methods.

\begin{tabular}{|l|c|c|c|}
\hline $\begin{array}{l}\text { Method } \\
\text { Acceptability }\end{array}$ & $\begin{array}{c}\text { Medical } \\
\text { method }\end{array}$ & MVA & p-value \\
\hline Success rate & $58(93.55 \%)$ & $37(97.3 \%)$ & .7 \\
\hline Satisfaction & $57(91.9 \%)$ & $34(89.5 \%)$ & 0.06 \\
\hline $\begin{array}{l}\text { Recommending } \\
\text { to others }\end{array}$ & $57(91.9 \%)$ & $34(89.5 \%)$ & 0.06 \\
\hline Reuse if required & $57(91.9 \%)$ & $34(89.5 \%)$ & 0.06 \\
\hline
\end{tabular}

Success rate of MVA was slightly more than that of medical method, though it was not statistically significant. MVA is faster and simpler method and results are comparable with study done by Nhu Ngoc et $\mathrm{al}^{6}$. Medical method is having success rate $93.3 \%$ which is comparable with study done by Sreeja GR at $\mathrm{el}^{7}$. The satisfaction, recommendation to others and reuse if required is more with medical method than MVA, though no significant difference was found statistically. For these three factors result are comparable with study of Qamariya Ambusidi et al for medical method. 
Table No. 8: Comparison of complications in both methods.

\begin{tabular}{|l|c|c|}
\hline Complications & Medical method & MVA \\
\hline Blood transfusion & 0 & 0 \\
\hline Uterine perforation & 0 & 0 \\
\hline Cervical injury & 0 & 0 \\
\hline
\end{tabular}

No major complications occur in either of the method. Results are comparable for medical method with Qamariya Ambusidi et al ${ }^{9}$ and for MVA comparable with Ritu G Nayak et al ${ }^{10}$.

\section{Discussion}

During our study period medical abortion 62\% was preferred by more women than manual vacuum aspiration $38 \%$, the finding is in concordance with other studies by Mulatu et al comparing MVA and medical method ${ }^{5}$. Reason to choose medical method was to avoid pain and surgery. Patient also felt that observed that privacy was maintained and it was more convenient. Reason to choose MVA was that it was faster and simpler and no repeated visits were required. In our study women living in rural area preferred MVA, most probably to avoid repeated visits. This is comparable to the study by Mulatu et $\mathrm{al}^{5}$. According to education status highly educated women preferred medical method as seen in study done by Mulatu et al. Reasons to choose MVA were single visit, high success rate, faster and simple and no drug side effects and results are comparable with studies done by Nhu Ngoc et $\mathrm{al}^{6}$. It was observed that no significant difference was detected in method choice in women of different socio-economic class. A significant difference was observed in women of lower middle class for preference of medical method ( $p$ value $<0.01$ ) need further evaluation.

It was observed that medical method caused more nausea; vomiting \& diarrhea which was drug induced side effects as compared to MVA. The duration of bleeding was also more in medical method as compared to MVA $(6.7 \pm 5$ days vs $3.6 \pm 3$ days). However pain felt by patient choosing MVA was significantly more than with medical method.
There were no complications like cervical injury, uterine perforation or need of blood transfusion in present study. Results were comparable with study done by Rita G Nayak et al.

Success rate in MVA is $100 \%$, however in our study it is $97.1 \%$ with 1 case of incomplete abortion. The reason could be that procedure done in minor OT under paracervical block. Abortion rate with medical method was $93.5 \%$ which is comparable with study done by Irving M Spitz at $\mathrm{al}^{11}$.

Satisfaction rate in our study was somewhat equal. Although there is high incidence of minor side effects with high dose of Mesoprostol, still there is higher satisfaction rate. Medical method and MVA both methods of abortion are effective and safe for early pregnancy termination.

\section{Conclusion}

Every woman has the joy of pregnancy if it is wanted but it is stress if unwanted. Medical method of abortion and MVA both are safe and effective methods of termination of early pregnancy. It can be recommended that all women seeking termination of early pregnancy should be given informed choice between medical method and MVA. These both methods safe and easy procedures and do not require any special skill.

In India, the bill on MTP was passed in 1971 and brought into execution on April 1972. The law is quite liberal, as to reduce illegal abortion hence, maternal mortality. Vacuum aspiration was the popular method for first trimester abortion till Mifepristone and Misoprostol were approved by USFDA in 2000 for first trimester abortion. The drug controller of India has also approved their use for medical abortion up to 49 days amenorrhea in 2002. Medical abortion regime is safe and convenient to be used as an alternative to manual vacuum aspiration.

There were few limitations to this study. The number of clients involved was less. The two study groups were not matched for confounding variables, no randomization or blinding while assigning the group. The complications were 
reported by clients and were susceptible to subjective variation. The duration of bleeding and time of expulsion of retained product of conception from medication/surgical intervention was not studied.

\section{References}

1. Society of Obstetrics and gynecology: Induced abortion Guidelines. Journal Obstet Gynaecol Can. 2006;184:1014-27.

2. Unsafe abortions: global and regional estimates of incidence of unsafe abortion and associated mortality in 2008, World Health Organization, Geneva, 2011.

3. Safe abortion: technical and policy guidance for health system, World Health Organization, Geneva, 2003.

4. Tasnim N, Mahmud G, Fatima S, Sultana M. Manual vacuum aspiration: a safe and cost effective substitute of electric vacuum aspiration for surgical management of early pregnancy loss. J Pak Med Assoc Feb 2016; 61 (2): 149-53.

5. Mulatu AW, Tegbar YS, Mary TW, Desalegn TZ. Client preferences and acceptability for medical abortion and MVA as early pregnancy termination method in Northwest Ethopia. Reproductive Health 2011; 8: 19-23.

6. Ngoc N, Winikoff B, Clark S, Ellettson C, Am K, Hieu D, Elul: Safety, efficacy and acceptability of Mifepristone-Misoprostol medical abortion in Vietman. Int Fam Plan Prospect 1999, 25(1):10-14.

7. Sreeja GR, Vargese P, Anitha KG. Mifepristone pus vaginal Misoprostol versus Mesoprostol alone for medical termination of pregnancy. India $\mathbf{J}$ of clinical practice.2013Dec; 24(7):1-7.
8. Elzaher MA, Bedew M. Mannual vaccum aspiration: a safe and cost effective substitute for dialation and curettage on the surgical management of first trimester abortion. J of American Science.2013;9 (6):581-85.

9. Ambusidi Q \& Zutshi A. Effectiveness of mesoprostol for induction of first trimester miscarriage. Sultan Qaboos University Med J.2015; 15(4):534-38.

10. Nayak RG, Patil SP, Patil SK, Kashirsagar $\mathrm{N}$. A comparison of manual aspiration with medical method of termination of pregnancy upto 9 weeks of gestational age. International Journal of Recent trends in science And technology.2015; 13(3):49094.

11. Spitz IM, Bardin CW, Benton L, Robbins A. Early pregnancy termination with mifepristone and mesoprostol in United States. N Eng J Med.1998; 338:1241-7. 